\title{
Multidimensional Seismic Control by Tuned Mass Damper with Poles and Torsional Pendulums
}

\author{
Haoxiang He, ${ }^{1,2}$ Wentao Wang, ${ }^{1}$ and Honggang $\mathrm{Xu}^{1}$ \\ ${ }^{1}$ Beijing Key Laboratory of Earthquake Engineering and Structural Retrofit, Beijing University of Technology, Beijing 100124, China \\ ${ }^{2}$ Beijing Collaborative Innovation Center for Metropolitan Transportation, Beijing 100124, China
}

Correspondence should be addressed to Haoxiang He; hhx7856@163.com

Received 4 November 2016; Accepted 18 January 2017; Published 6 March 2017

Academic Editor: Jeong-Hoi Koo

Copyright (C) 2017 Haoxiang He et al. This is an open access article distributed under the Creative Commons Attribution License, which permits unrestricted use, distribution, and reproduction in any medium, provided the original work is properly cited.

Due to the eccentric characteristics and the torsional excitation of multidimensional earthquakes, the dynamic response of asymmetry structure involves the translation-torsion coupling vibration and it is adverse to structural performance. Although the traditional tuned mass damper (TMD) is effective for decreasing the translational vibration when the structure is subjected to earthquake, its translation-torsion coupled damping capacity is still deficient. In order to simultaneously control the translational responses and the torsional angle of asymmetry structures, a new type of tuned mass damper with tuned mass blocks, orthogonal poles, and torsional pendulums (TMDPP) is proposed. The translation-torsion coupled vibration is tuned by the movement of the mass blocks and the torsional pendulums. According to the composition and the motion mechanism of the TMDPP, the dynamic equation for the total system considering eccentric torsion effect is established. The damping capacity of the TMDPP is verified by the time history analysis of an eccentric structure, and multidimensional earthquake excitations are considered. The damping effect of the traditional TMD and the TMDPP is compared, and the results show that the performance of TMDPP is superior to the traditional TMD. Moreover, the occasional amplitude amplification in TMD control does not appear in the TMDPP control. The main design parameters which affect the damping performance of TMDPP are analyzed.

\section{Introduction}

Earthquake generates uncountable loss and damage to human beings and society; one of the main causes of the loss of life and property is the damage and the destruction of building structures. Therefore, it is significant to intensively study the dynamic effect of ground motion on structure. In recent years, with the diversification of building function, complex shape and asymmetric building structures in the seismic area are increasing, and the center of mass (CM) and the center of stiffness (CS) of these structures are not coincident. When these structures are subjected to the horizontal earthquakes, the resultant action of inertia force of the structure acts on the center of mass, and the resultant action of the resilience of lateral resisting element acts on the center of stiffness $[1,2]$. Hence, the structures vibrate not only in the horizontal directions but also in the torsional direction around the center of stiffness, and the translationtorsion coupling vibration inevitably occurs [3]. Therefore, under the strong earthquake, the torsional vibration of the unsymmetrical structure can cause the serious damage or collapse of the building.

In addition, when the seismic waves pass through the bedrock and the ground surface, the difference between the period and the phase of each ground point brings about the rotational component besides the horizontal components, so the earthquake itself produces the torsional motion [4]. Even for most symmetric structures, due to the mass accidental eccentricity caused by the structure weight and the actual distribution of loading, and the stiffness accidental eccentricity caused by the variation of the structural material properties, the error of the component size, and the construction condition, the actual structure also has the eccentric effect. Therefore, the vibration control of the translation-torsion 
coupling response and torsional vibration of the building structure has become the research hotspot.

To reduce the torsional response of the eccentric structure, the structure layout is adjusted and the torsional stiffness of the structure is strengthened according to the traditional earthquake design method. However, in the case of building function which has been determined and the arrangement of the structure which is very limited, the increase of torsional stiffness will induce the enlargement of the sections of the components and the increase of construction costs and even the increase of seismic action. Hence, the traditional design method cannot effectively solve the problem of torsional vibration of the eccentric structure under earthquake.

Structural control is the new protection technology which can change or adjust the dynamic characteristic or dynamic action by installing devices, mechanisms, substructure, or supplying external force in a certain part of the structure $[5,6]$. Structural control provides a safe and effective way to enhance the aseismic capacity of structures. At present, it has been verified that the structural responses can be reduced by the control technology such as base isolation, energy dissipation damper, tuned damper, and active control [79]. However, most of the research focus on the horizontal vibration control of the structure and rarely involve the problem of torsional vibration. In fact, there are quite a number of building structure damage due to the seismic torsional responses, and the torsional responses may be the main factor of earthquake damage under certain conditions. Therefore, it is necessary to develop new technology and devices to control the torsional vibration [10].

The tuned control devices such as tuned mass damper (TMD) and tuned liquid damper (TLD) have been extensively studied and widely applied because the construction and the mechanism of the tuned damper is simple and definite. The most commonly used and most effective tuned damper is tuned mass damper, which is a vibration system composed of springs or slings, mass block, and damper, and it can be installed in a specific location on the structure. Since its natural frequency is similar to one of the main structures, the TMD system can reduce the vibration amplitude of the main structure by means of generating the resonance with the controlled modes of the main structure when the structure is subjected to wind load or earthquake. The tuned mass dampers have been applied in the civil engineering such as high-rise buildings, tower structures, and long-span bridges.

The composition and function of the traditional TMD are gradually improved. Xu and Igusa proposed the concept of multiple TMDs (MTMDs) with different tuned frequencies to control the structural dynamic responses [11]. Abé and Igusa presented the design formula of MTMDs in various load cases [12]. Li et al. systematically studied the parameter optimization of the MTMD, such as the combination mode and the distribution effect of mass, stiffness, and damping ratio $[13,14]$.

Though the theoretical research and engineering application have proved that the TMD system and the MTMDs can effectively decrease the dynamic response of structure, there still exist some deficiencies in the classic TMDs, especially in inadequate damping capacity for higher order modes and performance for multiple dimensional control or torsional control [15-17].

Singh et al. presented an approach for optimum design of four tuned mass dampers for response control of torsional building systems subjected to bidirectional seismic inputs, and the TMDs are installed in pairs along two orthogonal directions [18]. A genetic algorithm is used to search for the optimum parameter values for the four dampers. The numerical results showed the optimum design scheme is effective. Similar to the above ideas, Ahlawat and Ramaswamy [19] proposed an absorber system which consists of four TMDs arranged in the way that the system can control the torsional mode of vibration effectively in addition to the flexure modes.

Taking into account the even placement of the MTMD within the width of the asymmetric structure, $\mathrm{Li}$ and $\mathrm{Qu}$ discussed the effects of the normalized eccentricity ratio on the performance of the MTMD, and the optimum parameters of MTMD are given for the reduction of the translational and torsional response of structures [20].

Almazán et al. studied the response of asymmetrical linear and nonlinear structures subjected to unidirectional and bidirectional seismic excitation, equipped with one or two TMDs [21]. The optimized parameters of each TMD are obtained by applying the concept of general torsional balance. The results show that the optimized TMDs reduce the edge deformation significantly. In addition, for torsional hybrid and flexible structures, the optimized TMD position is sensitive to inelasticity of the main structure.

Lin et al. proposed bidirectional coupled tuned mass dampers (BiCTMDs) for the seismic response control of asymmetric-plan buildings subjected to bidirectional ground motions [22]. The numerical results show that the proposed BiCTMD is effective in reducing the seismic damage of inelastic asymmetric-plan buildings.

Wang and Lin have studied the applicability of multiple tuned mass dampers (MTMD) on the vibration control of irregular buildings modelled as torsional coupled structures due to base motions and the soil-structure interaction (SSI) effect [23]. The analysis results show that the increase of height-base ratio of an irregular building and the decrease of relative stiffness of soil to structure generally amplify both SSI and MTMD detuning effect, especially for the building with highly torsional coupled effect. He et al. have proposed a twodirectional horizontal and torsional TMD, which includes tuned mass blocks, torsional blocks, and rotation lever. The horizontal and torsional response of the building structure is controlled by the movement and the rotation of the multidimensional tuned mass damper in different directions [24].

Based on the current research, method, and engineering techniques, it can be found that the torsional response control by TMD has become an increasing concern and the improvements are basically realized through the use of several conventional TMDs or the optimization of the MTMDs. However, few studies focus on the innovation about the composition and the form of TMD or MTMDs according to the characteristics of structural eccentricity and the torsional response. Considering this research background, the tuned mass damper with orthogonal poles and torsional pendulums 


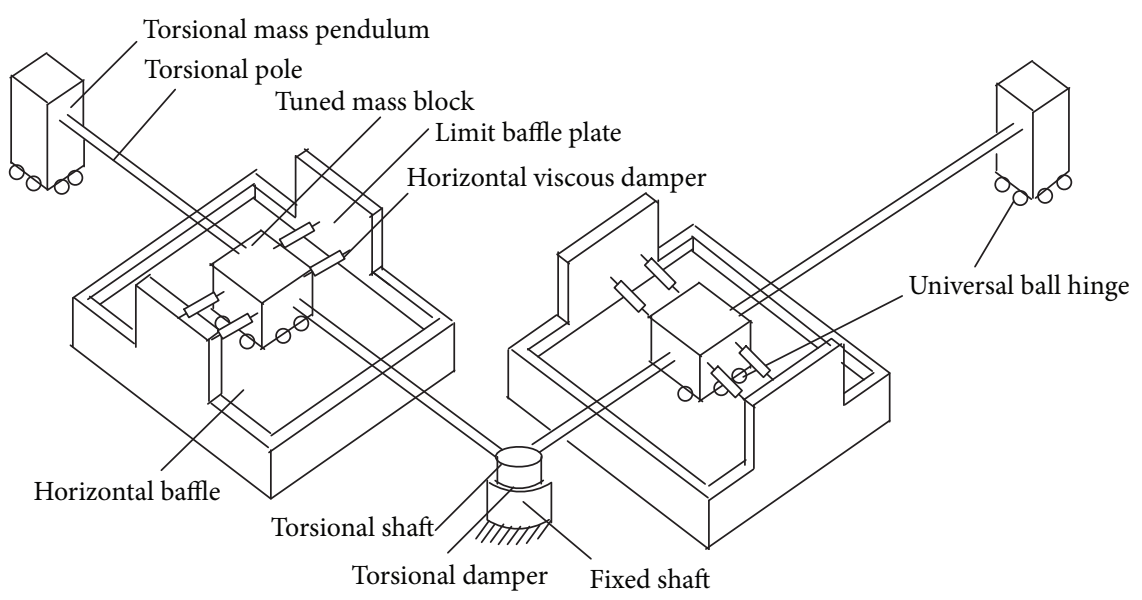

FIgURE 1: Composition of the TMDPP.

(TMDPP) which can reduce both the responses in the two horizontal directions and the amplitude in torsional direction is proposed in this study. The numerical analysis results show that the TMDPP can effectively decrease the coupling vibration by reasonable design and arrangement. Compared with other passive control systems such as structure with bucklingrestrained braces or viscous energy dissipation braces, the displacements of top floors the torsional vibration of the total structure can be effectively controlled. Generally, TMDPP is especially suitable for low-rise buildings and shear-type structure.

\section{Composition and Capacity of TMDPP}

The torsional damping capacity of TMD is usually ignored because the conventional TMD is designed for one horizontal direction. In order to overcome this limitation, a new type of tuned mass damper with orthogonal poles and torsional pendulums (TMDPP) which can decrease the dynamic responses in two horizontal directions and torsional direction is proposed.

This damper consists of two tuned mass blocks along two horizontal axes of the structure, two torsional mass pendulums, two orthogonal torsional poles, the horizontal dampers, limit baffle plates, and other auxiliary components. The structural map of TMDPP is shown in Figure 1.

Two tuned mass blocks are arranged on the top of the structure along the two horizontal axes, respectively. As a general rule, the TMDPP must be located towards the corner (edge) whose deformation prevails in the uncontrolled condition. Therefore, in torsional rigid structures with medium or large eccentricities, the TMDPP tends to be located towards the flexible corner (edge), so as to control the horizontaltorsional coupled vibration.

The tuned mass blocks are linked with the limit baffle plates by the horizontal viscous damper with appropriate damping and stiffness to ensure the mass blocks can oscillate alternately and rapidly. Meanwhile, the tuned mass blocks are assembled with the universal ball hinges to enable the blocks move smoothly and rotate slightly with the torsional poles in the flat plane. The torsional mass pendulums are connected with the tune mass blocks and the torsion shaft by the torsional poles, and the whole mechanism can be rotated freely in the horizontal plane. The torsional pendulums are connected with the structural roof through the universal ball hinges to ensure that the torsional poles remain horizontal in the normal state.

The torsional dampers between the torsion shaft and the fixed shaft can provide suitable damping to enhance the energy dissipation capacity of the whole system. When the structure is subjected to earthquake, the tuned mass blocks will move and produce the inertia force due to relative displacement and the viscous damper will produce damping force and restoring force, the resultant force of the above three kinds of forces will act on the structure, so the structural responses will attenuate in the two horizontal directions. In the torsional direction, the rotational inertia force is generated by the rotation of the torsional mass pendulums and the mass blocks around the torsion shaft and the damping force from the torsional damper, and the action direction is opposite to the torsional response of the structure. Hence, both the horizontal responses and the torsional responses can be effectively controlled by TMDPP.

Compared with the conventional tuned mass dampers, the tuned mass damper with orthogonal poles and torsional mass pendulums (TMDPP) presented in this study has the following advantages: (1) the tuned mass blocks and the torsional pendulums can slide in the horizontal directions and the torsional direction, so both the horizontal kinetic energy and the rotational energy of the main structure can be transferred and dissipated, so the multidimensional control can be realized and the damping capacity is enhanced. (2) The torsional damping is achieved by the rotation of the poles and the pendulums, and the control mode is flexible because the pole length, the damper parameter, and the location of the pendulums can be modulated according to the actual requirements and condition, so the multidimensional tuned vibration control of structure is realized conveniently. 


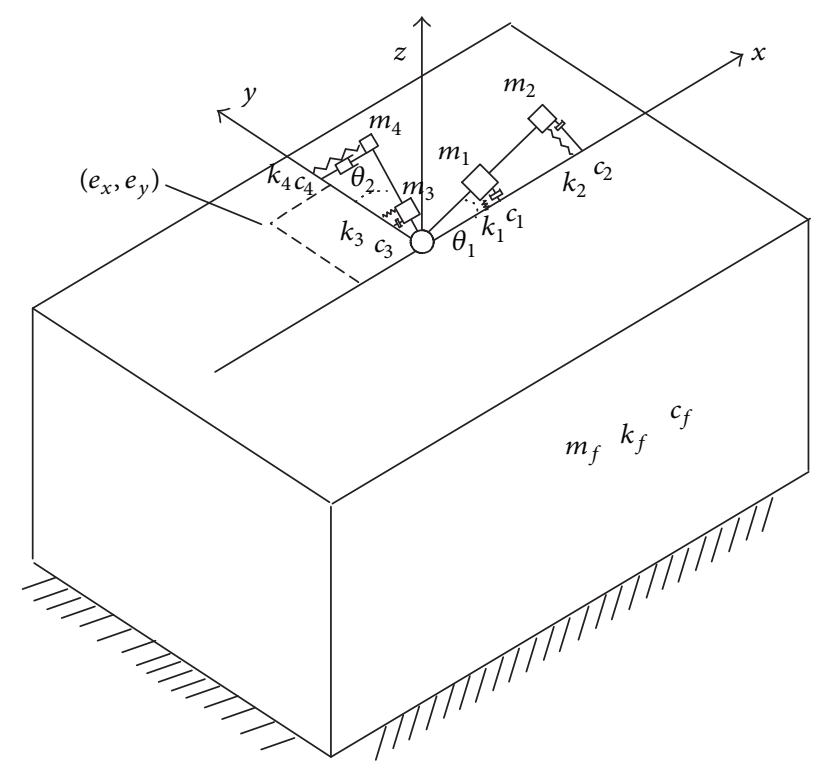

FIGURE 2: Equivalent dynamic system of eccentric structure with TMDPP.

\section{System Dynamic Equation of Structure with TMDPP}

In order to study the damping effect of the structure equipped with TMDPP, the actual main structure can be equivalent to a system with one-degree-of-freedom. The TMDPP is installed on the roof of the eccentric multilayer structure, as shown in Figure 2.

In the two horizontal directions and the torsional direction around the vertical axis, the main structure is simplified as one system with a single degree of freedom, respectively. The equivalent mass of the main structure can be calculated as the actual total mass. The equivalent stiffness can be calculated according the following steps: the horizontal stiffness and torsional stiffness of the beams, columns, walls, and the floor of each story can be calculated, respectively, and the equivalent parallel stiffness of all the members can be set as the layer stiffness. If each layer is viewed as the serial mass point of the system, the serial stiffness of all the layers is set as the global stiffness; thus, the global horizontal stiffness and the global torsional stiffness can be obtained, respectively. For the above equivalence method, the bending stiffness of the structure is usually ignored, and the firstorder model is only considered. If the structure is high-rise building or the high aspect ratio is relatively large, the model combination effect is obvious and the accuracy of equivalence may not be higher. In the traditional TMD analysis, it is usually assumed that the main body of the structure is a single degree of freedom. Therefore, the above equivalence method is basically reasonable.

The two orthogonal horizontal axes of the main structure are assumed as $x$ and $y$, respectively. The equivalent mass of the main structure is set as $m_{f}$, the equivalent horizontal stiffness of $x$ direction and $y$ direction is $k_{f x}$ and $k_{f y}$, the rotational inertia around the $z$-axis is $J_{f}$, and the inplane torsional stiffness is $k_{f \theta}$. The horizontal damping and torsional damping are $c_{f}$ and $c_{f \theta}$, respectively. In addition, since the structure is asymmetrical, $e_{x}$ and $e_{y}$ are set as the eccentricity of $x$-axis and $y$-axis, respectively. The tuned mass blocks and the torsional tuned pendulums, which can be simplified as the mass point with specified stiffness and damping, are assembled along the two horizontal axes of the main structure. For the tuned mass block along $x$-axis, the mass, the stiffness in two horizontal direction, the horizontal damping, the rotational damping, the rotational inertia, and the distance to the pole end are $m_{1}, k_{1 x}, k_{1 y}, c_{1}, c_{1 \theta}, J_{1}$, and $a_{1}$, respectively. For the matching torsional tuned pendulums, the corresponding parameters are $m_{2}, k_{2 x}, k_{2 y}, c_{2}, c_{2 \theta}, J_{2}$, and $l_{1}$, respectively. On the other hand, for the tuned mass block along $y$-axis, the mass, the stiffness in two horizontal direction, the horizontal damping, the rotational damping, the rotational inertia, and the distance to the pole end are $m_{3}, k_{3 x}, k_{3 y}, c_{3}, c_{3 \theta}, J_{3}$, and $a_{2}$, respectively. For the matching torsional tuned pendulums, the corresponding parameters are $m_{4}, k_{4 x}, k_{4 y}, c_{4}, c_{4 \theta}, J_{4}$, and $l_{2}$, respectively.

The dynamic response of torsional tuned pendulums can be calculated according to the response of the tuned mass block in the corresponding direction because the poles are rigid, and the length conversion factor in $x$ direction and $y$ direction is assumed as $\beta_{1}=l_{1} / a_{1}$ and $\beta_{2}=$ $l_{2} / a_{2}$, respectively. Then the coupling effect of the main structure and the TMDPP in the two horizontal directions and torsional direction are taken into account; according to the principle of D'Alembert, the multidimensional dynamic equation of the total system is deduced as follows:

$$
\mathbf{M U}+\mathbf{C} \dot{\mathbf{U}}+\mathbf{K U}=-\mathbf{M}_{g} \ddot{\mathbf{U}}_{g}(t)
$$

in which $\mathbf{M}, \mathbf{C}$, and $\mathbf{K}$ are the global mass matrix, the global damping matrix, and the global stiffness matrix, respectively, and the dimension is $9 \times 9$. $\mathbf{M}_{g}$ is the mass participated matrix; the dimension is $9 \times 3$. $\ddot{\mathbf{U}}_{g}(t)=\left[\ddot{\mathbf{U}}_{g x}, \ddot{\mathbf{U}}_{g y}, \ddot{\mathbf{U}}_{g \theta}\right]^{T}$ is the ground motion vector, $\ddot{\mathbf{U}}_{g x}, \ddot{\mathbf{U}}_{g y}$, and $\ddot{\mathbf{U}}_{g \theta}$ are the ground motion in $x, y$, and torsional direction, respectively. $\mathbf{U}=$ $\left[x_{f}, x_{1}, x_{3}, y_{f}, y_{1}, y_{3}, \theta_{f}, \theta_{1}, \theta_{3}\right]^{T}$ is the relative displacement vector. $x_{f}, y_{f}$, and $\theta_{f}$ are the displacement of the main structure relative to the ground in $x$-axis, $y$-axis, and rotation direction, respectively. $x_{1}$ and $x_{3}$ are the horizontal displacement of the tuned mass block arranged in $x$ direction and $y$ direction relative to the main structure in $x$-axis, respectively. $y_{1}$ and $y_{3}$ are the horizontal displacement of the tuned mass block arranged in $x$ direction and $y$ direction relative to the main structure in $y$ axis, respectively. $\theta_{1}$ and $\theta_{3}$ are the torsion angle of the tuned pendulum arranged in $x$ direction and $y$ direction relative to the structural roof, respectively.

In the above equation, the dynamic system is established based on the relative coordinate system, so the mass matrix and stiffness matrix are different from the traditional form of the system based on the absolute coordinate. After the derivation of dynamic equations, the detailed equation of $\mathbf{M}$ is given by 


$$
\mathbf{M}=\left[\begin{array}{ccc}
\mathbf{M}_{x} & \mathbf{0} & \mathbf{M}_{x J} \\
\mathbf{0} & \mathbf{M}_{y} & \mathbf{M}_{y J} \\
\mathbf{M}_{x J} & \mathbf{M}_{y J} & \mathbf{M}_{J}
\end{array}\right]
$$

in which the specific construction of these above submatrix can be written as follows:

$$
\begin{aligned}
& \mathbf{M}_{x}=\mathbf{M}_{y}=\left[\begin{array}{rrr}
m_{f}+\left(1+\beta_{1}\right) m_{1}+\left(1+\beta_{2}\right) m_{3} & \left(1+\beta_{1}\right) m_{1} & \left(1+\beta_{2}\right) m_{3} \\
\left(1+\beta_{1}\right) m_{1} & \left(1+\beta_{1}\right) m_{1} & 0 \\
\left(1+\beta_{2}\right) m_{3} & 0 & \left(1+\beta_{2}\right) m_{3}
\end{array}\right], \\
& \mathbf{M}_{J}=\left[\begin{array}{ccc}
J_{f}+J_{1}+J_{2}+J_{3}+J_{4} & J_{1}+J_{2} & J_{3}+J_{4} \\
J_{1}+J_{2} & J_{1}+J_{2} & 0 \\
J_{3}+J_{4} & 0 & J_{3}+J_{4}
\end{array}\right], \\
& \mathbf{M}_{x J}=\left[\begin{array}{ccc}
0 \\
\left(m_{1}+\beta_{1} m_{2}\right) y_{1}+\left(m_{1} a_{1}+m_{2} l_{1}\right) \sin \theta_{1} & \left(m_{1}+\beta_{1} m_{2}\right) y_{1}+\left(m_{1} a_{1}+m_{2} l_{1}\right) \sin \theta_{1} & 0 \\
\left(m_{3}+\beta_{2} m_{4}\right) y_{3}+\left(m_{3} a_{2}+m_{4} l_{2}\right) \cos \theta_{2} & 0 & \left(m_{3}+\beta_{2} m_{4}\right) y_{3}+\left(m_{3} a_{2}+m_{4} l_{2}\right) \cos \theta_{2}
\end{array}\right],
\end{aligned}
$$

$\mathbf{M}_{y J}$

$$
=\left[\begin{array}{ccc}
0 & 0 & 0 \\
-\left(m_{1}+\beta_{1} m_{2}\right) x_{1}-\left(m_{1} a_{1}+m_{2} l_{1}\right) \cos \theta_{1}-\left(m_{1}+\beta_{1} m_{2}\right) x_{1}-\left(m_{1} a_{1}+m_{2} l_{1}\right) \cos \theta_{1} & 0 \\
-\left(m_{3}+\beta_{2} m_{4}\right) x_{3}-\left(m_{3} a_{2}+m_{4} l_{2}\right) \sin \theta_{2} & 0 & -\left(m_{3}+\beta_{2} m_{4}\right) x_{3}-\left(m_{3} a_{2}+m_{4} l_{2}\right) \sin \theta_{2}
\end{array}\right] \text {, }
$$

$$
\mathbf{M}_{g}=\left[\begin{array}{lll}
\mathbf{M}_{g 1} & \mathbf{M}_{g 2} & \mathbf{M}_{g 3} \\
\mathbf{M}_{g 2} & \mathbf{M}_{g 1} & \mathbf{M}_{g 4} \\
\mathbf{M}_{g 5} & \mathbf{M}_{g 6} & \mathbf{M}_{g 7}
\end{array}\right]
$$$$
\mathbf{M}_{g 1}=\left[-m_{f}-m_{1}-m_{2}-m_{3}-m_{4},-m_{1}-m_{2},-m_{3}-m_{4}\right]^{T},
$$$$
\mathbf{M}_{g 2}=[0,0,0]^{T},
$$$$
\mathbf{M}_{g 3}=\left[0,-\left(m_{1}+\beta_{1} m_{2}\right) y_{1}-\left(m_{1} a_{1}+m_{2} l_{1}\right) \sin \theta_{1},-\left(m_{3}+\beta_{2} m_{4}\right) y_{3}-\left(m_{3} a_{2}+m_{4} l_{2}\right) \cos \theta_{2}\right]^{T},
$$$$
\mathbf{M}_{g 4}=\left[0,\left(m_{1}+\beta_{1} m_{2}\right) x_{1}+\left(m_{1} a_{1}+m_{2} l_{1}\right) \cos \theta_{1},\left(m_{3}+\beta_{2} m_{4}\right) x_{3}+\left(m_{3} a_{2}+m_{4} l_{2}\right) \sin \theta_{2}\right]^{T},
$$$$
\mathbf{M}_{g 5}=\left[0,-\left(m_{1}+\beta_{1} m_{2}\right) y_{1}-\left(m_{1} a_{1}+m_{2} l_{1}\right) \sin \theta_{1},-\left(m_{3}+\beta_{2} m_{4}\right) y_{3}-\left(m_{3} a_{2}+m_{4} l_{2}\right) \cos \theta_{2}\right]^{T},
$$$$
\mathbf{M}_{g 6}=\left[0,-\left(m_{1}+\beta_{1} m_{2}\right) x_{1}-\left(m_{1} a_{1}+m_{2} l_{1}\right) \cos \theta_{1},\left(m_{3}+\beta_{2} m_{4}\right) x_{3}+\left(m_{3} a_{2}+m_{4} l_{2}\right) \sin \theta_{2}\right]^{T},
$$$$
\mathbf{M}_{g 7}=\left[-J_{f}-J_{1}-J_{2}-J_{3}-J_{4},-J_{1}-J_{2},-J_{3}-J_{4}\right]^{T} .
$$

Among (1), the stiffness matrix $\mathbf{K}$ is the symmetric matrix, and the main diagonal vector is $\left[k_{f x}\right.$, $k_{1 x}+\beta_{1} k_{2 x}, k_{3 x}+\beta_{2} k_{4 x}, k_{f y}, k_{1 y}+\beta_{1} k_{2 y}, k_{3 y}+\beta_{2} k_{4 y}, k_{f \theta}+$ $\left.k_{f x} e_{y}^{2}+k_{f y} e_{x}^{2}, k_{1 \theta}, k_{3 \theta}\right]$, and besides the above, the location of the other elements in stiffness matrix is zero. The corresponding vector of structural torsion angle is $\left[k_{f x} e_{y}, 0,0, k_{f y} e_{x}, 0,0, k_{f \theta}+k_{f x} e_{y}^{2}+k_{f y} e_{x}^{2}, 0\right.$, $0]$. Hence, the stiffness matrix is given by 


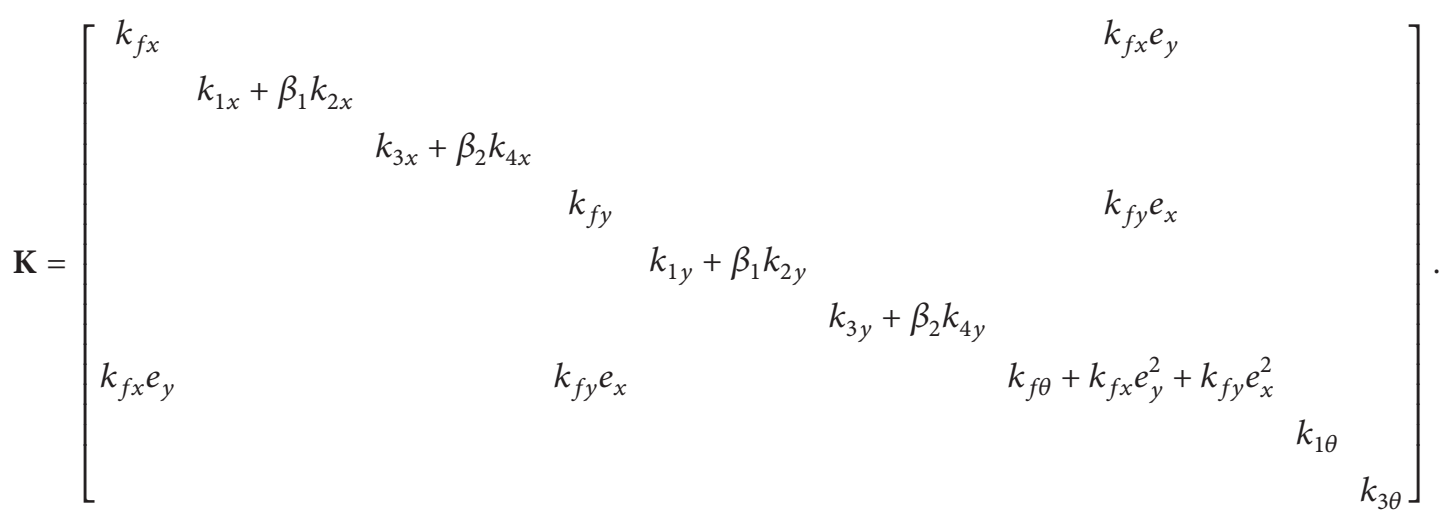

The global damping matrix may be written as

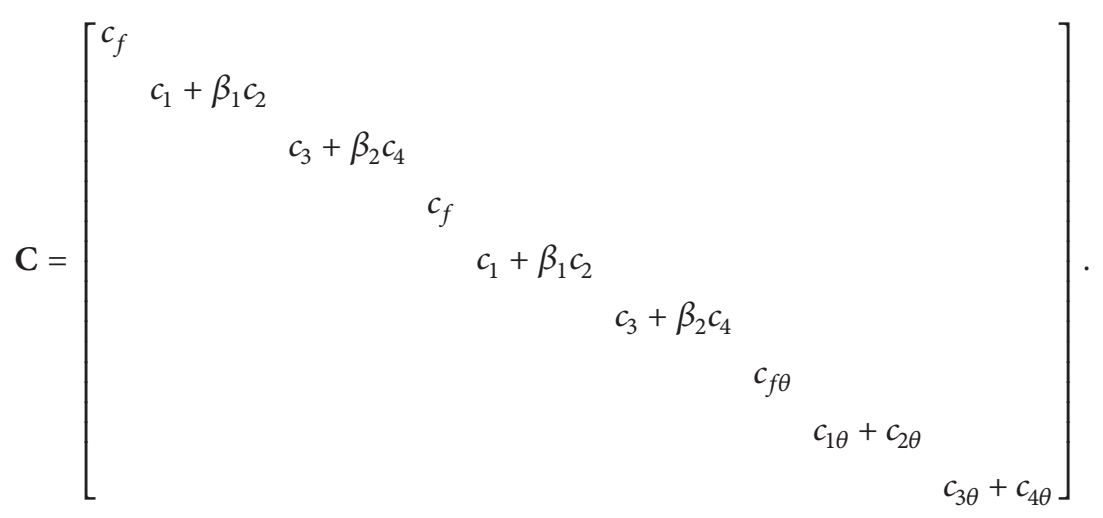

The dynamic equation can be solved according to the multiple-dimension ground acceleration and time history analysis method. Finally, the coupled dynamic response of the structure and the TMDPP can be obtained.

In view of the adoption for practical applications, a design procedure of the TMDPP is proposed. The main steps of the proposed design procedure of structure with TMDPP are summarized below:

(1) Calculate the equivalent mass, the horizontal stiffness, the torsional stiffness, and the damping of the structure according to equivalent method; then calculate the two horizontal periods and torsional period.

(2) Calculate the location of the center of stiffness and the location of the center of mass.

(3) Determine the mass ratio of TMDPP according to the engineering requirements and the actual conditions. Determine reasonable distribution of the tuned mass blocks and the torsional pendulums. Relative to the center of stiffness, the location of the TMDPP should be installed in the diagonal direction of the center of mass.
(4) Determine the length of the two orthogonal torsional poles and the length conversion factor.

(5) Determine the equivalent translational damping and torsional damping of the viscous dampers and TMDPP. Determine the principal axis equivalent stiffness and the equivalent torsional stiffness; ensure the actual periods of TMDPP coincide with the corresponding structural periods.

(6) Carry out the size and reinforcement design of the limit baffle plates and other auxiliary components.

(7) Verify the final damping effect and adjust the design parameters until the expected damping effect is obtained.

In addition, it is necessary to point out that the torsional excitation of the ground motion should be used in (1), but only the horizontal components and the vertical component can be obtained in the traditional ground motion database. The following method can be used to transform the existing translational ground motions into torsional component [25, 26], and the specific procedure is as follows:

(1) The included angle between the direction of the recorded components of the seismic station and 
the direction of the epicenter is $\alpha$; then the three components of the station can be decomposed into two motion components in the ground plane and the one component out of the plane according to the following equation:

$$
\left\{\begin{array}{l}
u_{1}(t) \\
u_{2}(t) \\
u_{3}(t)
\end{array}\right\}=\left[\begin{array}{ccc}
\cos \alpha & 0 & \sin \alpha \\
0 & 1 & 0 \\
\sin \alpha & 0 & \cos \alpha
\end{array}\right]\left\{\begin{array}{l}
u_{s 1}(t) \\
u_{s 2}(t) \\
u_{s 3}(t)
\end{array}\right\},
$$

where $u_{s 1}(t), u_{s 2}(t)$, and $u_{s 3}(t)$ are the two horizontal components and one vertical component which are recorded by station, and $u_{1}(t), u_{2}(t)$ are converted plane components, and $u_{3}(t)$ is the converted vertical component.

(2) Fast Fourier transform is applied to $u_{3}(t)$ and $u_{2}(t)$; obtain the Fourier spectrum of $U_{3}(\omega)$ and $U_{2}(\omega)$. For the given apparent wave velocity $c$, the Fourier spectrum of the rotational components $\Phi_{2}(\omega)$ and $\Phi_{3}(\omega)$ can be calculated according to $\Phi_{3}(\omega)=$ $i \omega U_{2}(\omega) / 2 c$ and $\Phi_{2}(\omega)=-i \omega U_{3}(\omega) / c$.

(3) The inverse Fourier transform is performed on $\Phi_{2}(\omega)$ and $\Phi_{3}(\omega)$; then the acceleration waves of rotational components are obtained by selecting the real parts. The apparent velocity value $c$ can be determined according to the following formula: $c=v / \sin \theta, v$ is the body wave propagation velocity, and the incident angle $\theta$ is the incident angle of the seismic wave on the ground surface. Taking into account the fact that $\theta$ is random variables, the value can be determined according to the statistical average of related seismic records by the harmonic method in the frequency domain.

\section{Analysis Example}

The integrated performance of the multidimensional vibration control with the tuned mass damper with orthogonal poles and torsional pendulums (TMDPP) is necessary to be verified. In this following analysis, one five-layer reinforced concrete frame is selected as a numerical example. The plane size of structure is $36 \mathrm{~m} \times 20 \mathrm{~m}$, the height of the first story is $3.6 \mathrm{~m}$, and the height of other stories is $3.0 \mathrm{~m}$, as shown in Figure 3. The section size of all the columns is $600 \mathrm{~mm}$ $\times 600 \mathrm{~mm}$, and the section reinforcement ratio is $2 \%$. The section size of the beams is $300 \mathrm{~mm} \times 600 \mathrm{~mm}$, and the section reinforcement ratio is $1.5 \%$. The thickness of each floor is $125 \mathrm{~mm}$. The axial compressive strength of concrete is $27.2 \mathrm{~N} / \mathrm{mm}^{2}$.

As shown in Figure 4, the center of mass (CM) of the whole structure matches the geometric center (CG), and the center of stiffness (CS) is located over the $x$-axis and $y$-axis at the distance of $5.0 \mathrm{~m}$ and $4.0 \mathrm{~m}$, respectively. The whole mass of the structure is $2.6 \times 10^{6} \mathrm{~kg}$. The equivalent stiffness in $x$ direction is $1.18 \times 10^{8} \mathrm{~N} / \mathrm{m}$, and the equivalent stiffness in $y$ direction is $1.42 \times 10^{8} \mathrm{~N} / \mathrm{m}$. The equivalent torsional stiffness is $1.32 \times 10^{10} \mathrm{~N} \cdot \mathrm{m}^{2}$ and the equivalent damping is

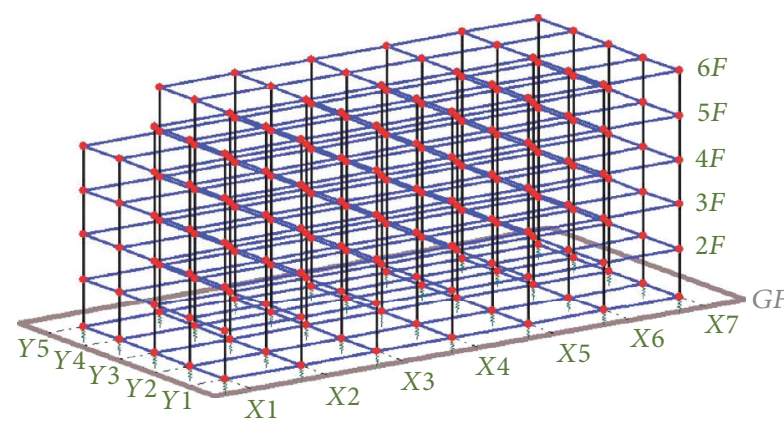

FIGURE 3: Side elevation of the reinforced concrete frames.

$9.75 \times 10^{5} \mathrm{~N} \cdot \mathrm{s} / \mathrm{m}$. The site type is hard soil. The seismic precautionary intensity is 8.0 , which means the structure may suffer from the earthquake whose exceeding probability of this intensity is $10 \%$ in the 50 -year period. The fundamental periods of the RC frame are $0.41 \mathrm{~s}$ in $x$ direction and $0.32 \mathrm{~s}$ in $y$ direction, respectively.

In order to resist the structural torsion, relative to the center of stiffness, the rational location of the TMDPP is in the diagonal direction of the coordinates of the center of mass, as shown in Figures 2 and 4.

According to the traditional research results and the conditions of practical engineering, the mass of TMDPP is proposed to be $3 \%-8 \%$ of total mass of the RC frame; thus, the final mass is set to $5 \%$ of the total structural mass. The lengths of the rigid poles in the orthogonal horizontal directions are designed according to the respective eccentricity and permitted space requirements. After consideration of engineering requirements and optimization design, the basic design parameters of TMDPP are shown in Table 1.

The RC frame structure is simplified as a single degree of freedom in each direction, and the coupling dynamic equation is established according to (1). In order to study and compare the damping performance of the TMDPP, a series of typical three-dimensional earthquake waves are selected because these ground motion records were collected from hard soil and the predominant periods are close to the structural period; then time history analysis is carried out. The details are listed in Table 2.

The rotational waves are computed according to the transformation method, as mentioned above. For example, the corresponding excitations of El Centro earthquake in different directions are shown in Figure 5. The corresponding acceleration response spectra of El Centro waves in different directions are shown in Figure 6. The time-frequency variation law in the rotational waves and its response spectra indicate the synthetic rotational waves are reasonable.

During the analysis, three different structures involving the original uncontrolled structure, the structure with single traditional TMD and the structure with TMDPP are considered, and the mass of the single TMD in the corresponding direction is equal to the total mass of the TMDPP. The multidimensional seismic responses of different structures and the damping effect of tuned mass dampers are obtained. 


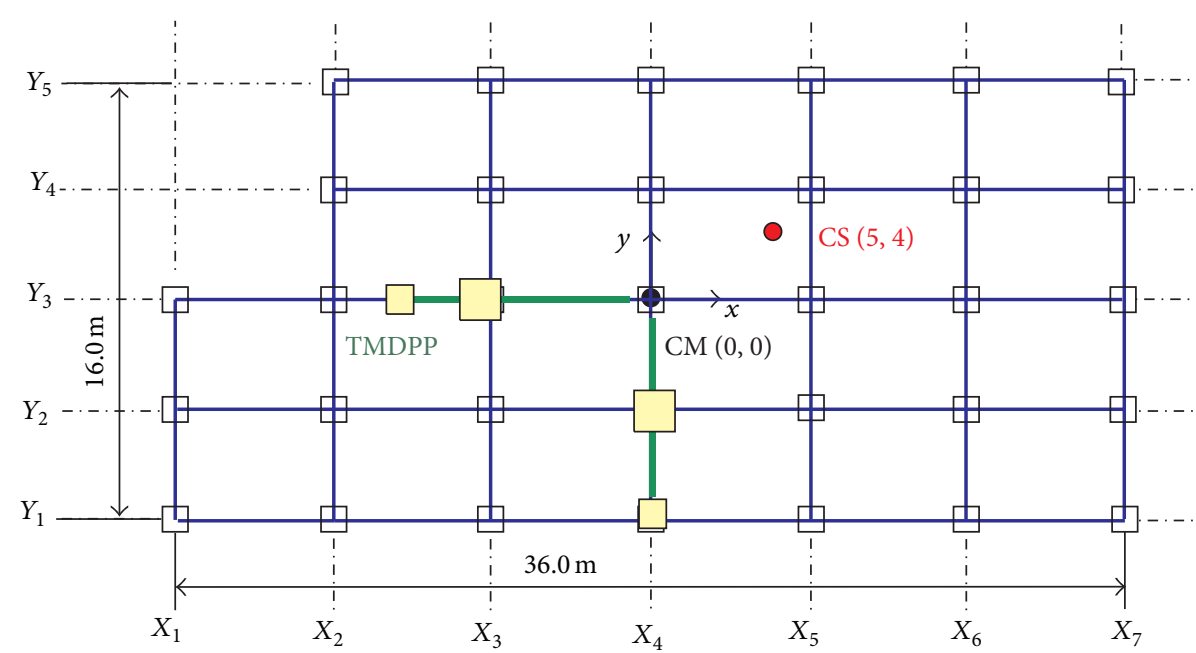

FIgURE 4: Arrangement position and scheme of TMDPP.

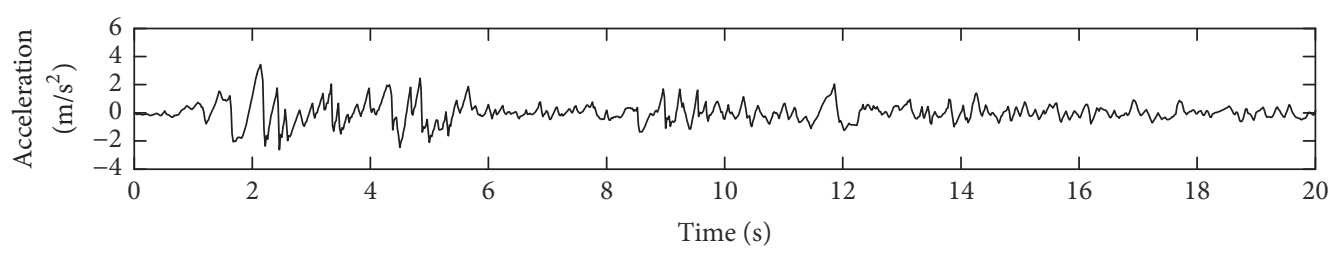

- $x$ direction

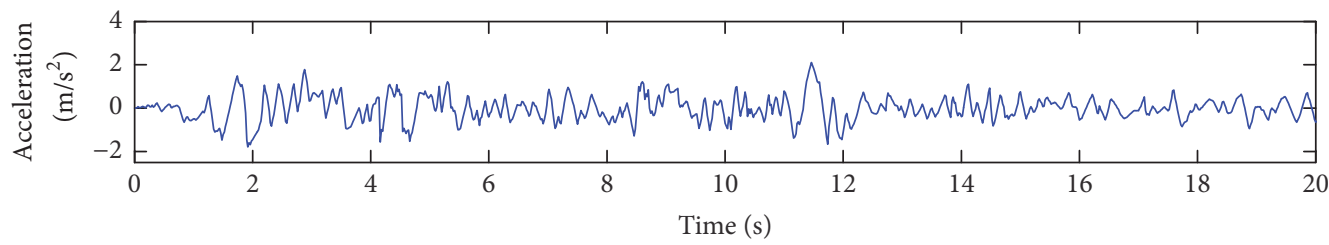

- $y$ direction
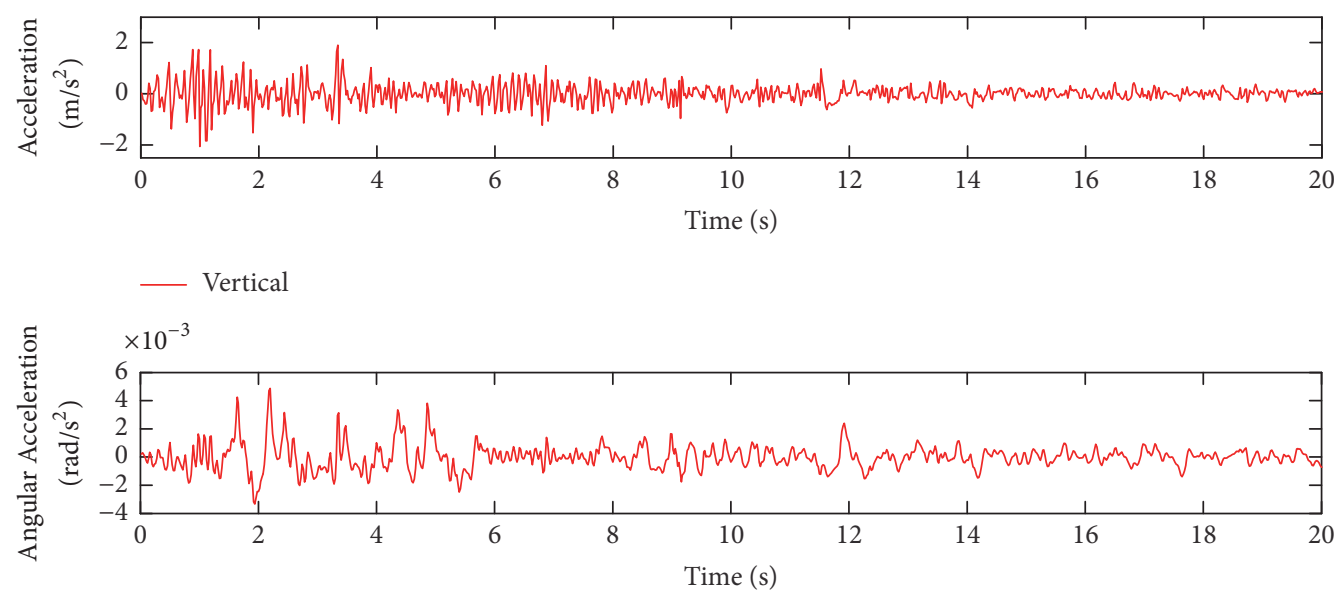

— Rotation

FIGURE 5: El Centro earthquake waves in different directions. 


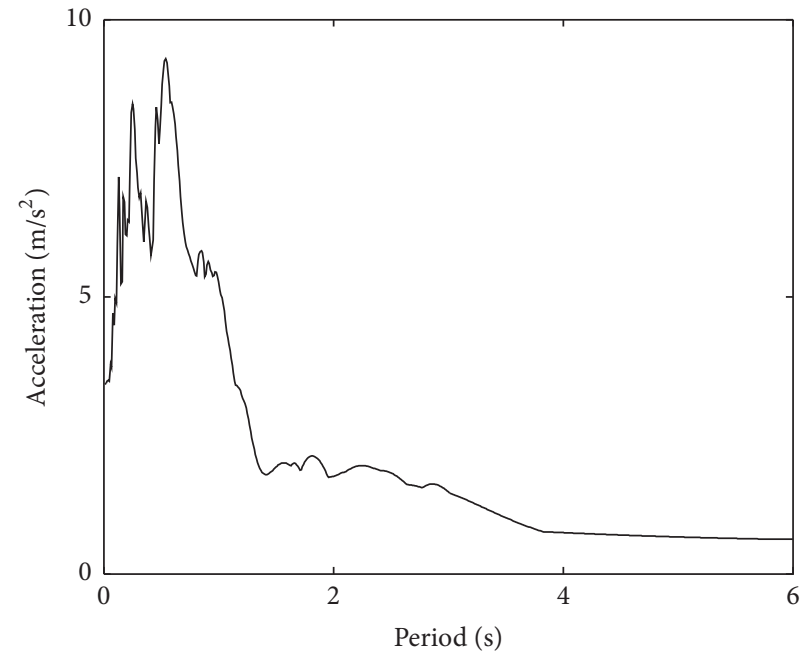

$-x$ direction

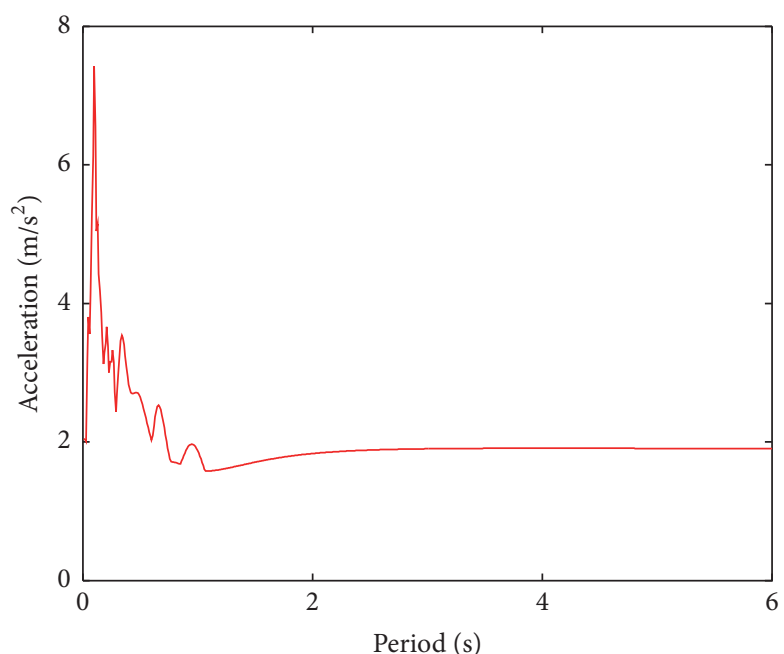

$z$ direction

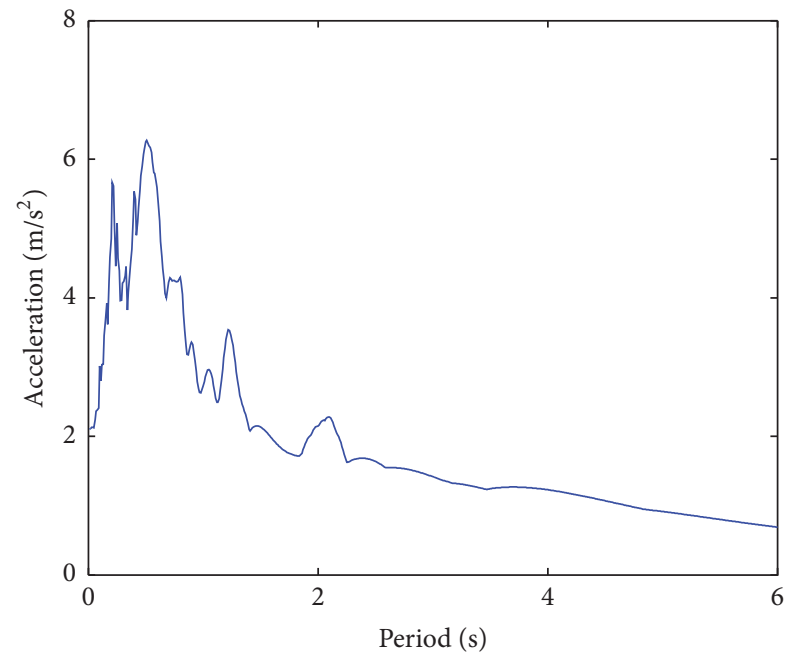

- $y$ direction

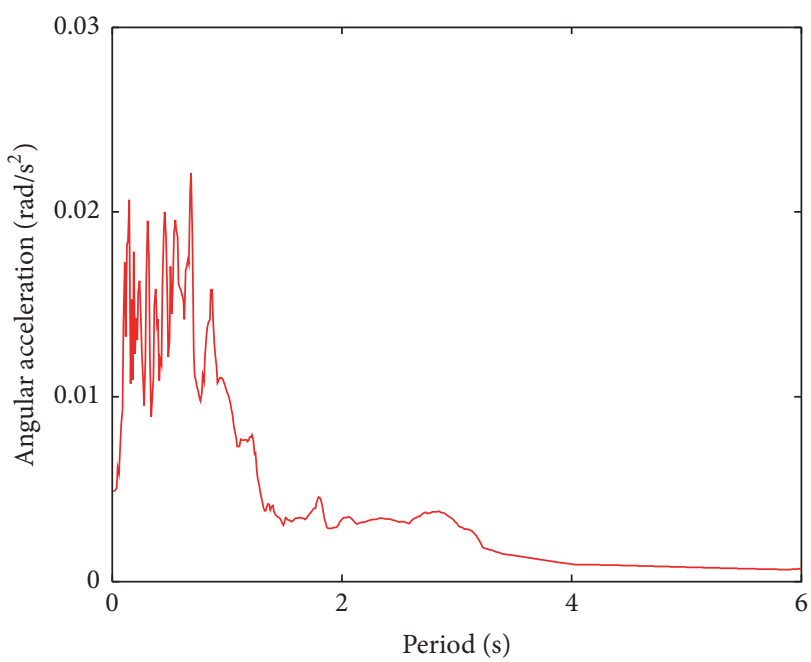

- Rotation

Figure 6: Acceleration response spectra of El Centro waves in different directions.

TABLE 1: Design parameter of TMDPP.

\begin{tabular}{|c|c|c|c|c|c|c|}
\hline \multirow[b]{2}{*}{ Mass parameters } & \multicolumn{6}{|c|}{ Design parameter } \\
\hline & $\begin{array}{c}\text { Mass ratio of } \\
\text { structure }\end{array}$ & $\begin{array}{c}\text { Principal axis } \\
\text { equivalent stiffness } \\
(\mathrm{N} / \mathrm{m})\end{array}$ & $\begin{array}{c}\text { Equivalent } \\
\text { torsional stiffness } \\
(\mathrm{N} / \mathrm{m})\end{array}$ & $\begin{array}{c}\text { Equivalent } \\
\text { translational damping } \\
(\mathrm{N} \cdot \mathrm{s} / \mathrm{m})\end{array}$ & $\begin{array}{c}\text { Equivalent } \\
\text { torsional damping } \\
(\mathrm{N} \cdot \mathrm{s} / \mathrm{m})\end{array}$ & $\begin{array}{l}\text { Distance to } \\
\text { fixed shaft }(\mathrm{m})\end{array}$ \\
\hline $\begin{array}{l}\text { Tuned mass block } \\
\text { in } x \text {-axis }\end{array}$ & 0.015 & $3.13 \times 10^{7}$ & $1.29 \times 10^{7}$ & $7.28 \times 10^{6}$ & $8.00 \times 10^{7}$ & 2 \\
\hline $\begin{array}{l}\text { Torsional } \\
\text { pendulum in } \\
x \text {-axis }\end{array}$ & 0.010 & $6.21 \times 10^{6}$ & $1.29 \times 10^{7}$ & $8.00 \times 10^{3}$ & $8.00 \times 10^{2}$ & 8 \\
\hline $\begin{array}{l}\text { Tuned mass block } \\
\text { in } y \text {-axis }\end{array}$ & 0.015 & $2.38 \times 10^{7}$ & $1.29 \times 10^{7}$ & $1.21 \times 10^{7}$ & $8.00 \times 10^{7}$ & 2 \\
\hline $\begin{array}{l}\text { Torsional } \\
\text { pendulum in } \\
y \text {-axis }\end{array}$ & 0.010 & $4.72 \times 10^{6}$ & $1.29 \times 10^{7}$ & $1.00 \times 10^{4}$ & $8.00 \times 10^{2}$ & 6 \\
\hline
\end{tabular}


TABLE 2: The ground motions used in this study.

\begin{tabular}{lcccc}
\hline Time & Earthquake name & Recording station & Magnitude $(\mathrm{MS})$ & \\
\hline 1940 & Imperial Valley, USA & El Centro & 6.5 & PGA $\left(\mathrm{m} / \mathrm{s}^{2}\right)$ \\
1952 & Kern County, USA & Taft & 7.2 & 3.42 \\
1985 & Michoacán & Tacy & 5.5 & 1.76 \\
\hline
\end{tabular}

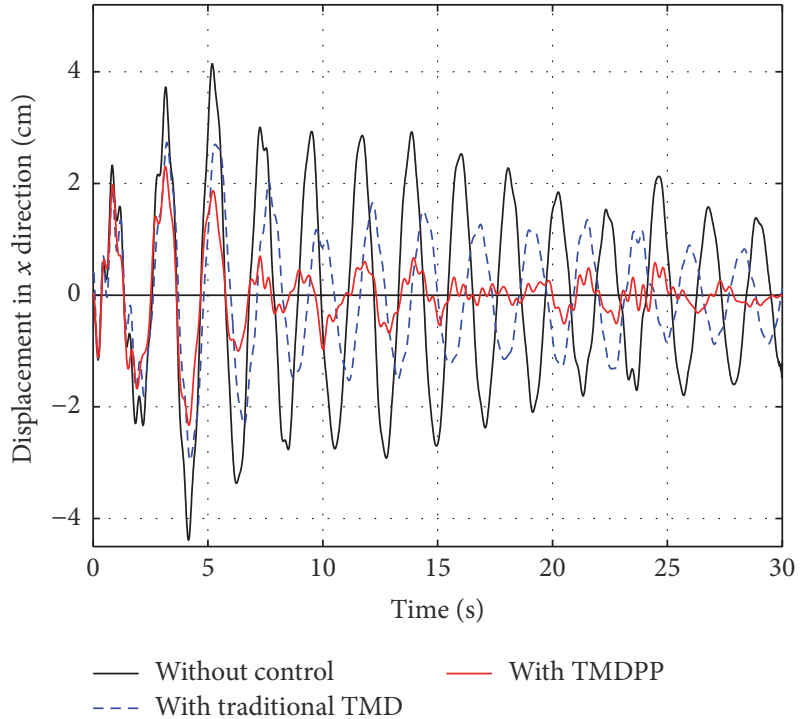

FIGURE 7: Damping comparison of structural displacement in $x$ direction.

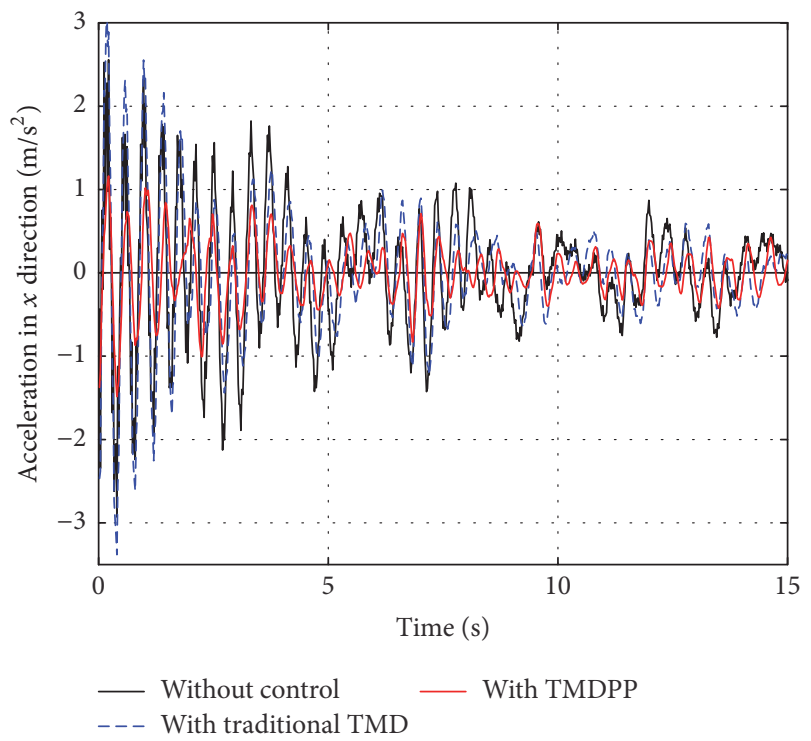

Figure 8: Damping comparison of structural acceleration in $x$ direction.

When the frame is subjected to El Centro earthquake, the result comparisons of the structural displacement and acceleration in $x$ direction are shown in Figures 7 and 8, respectively. The result comparisons of the corresponding responses in $y$ direction are shown in Figures 9 and 10,

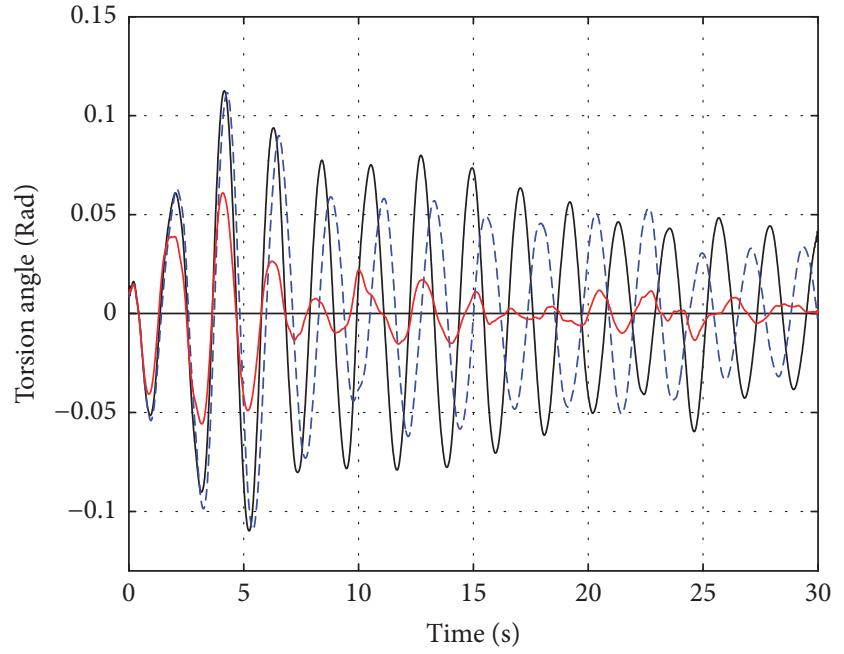

FIGURE 9: Damping comparison of structural displacement in $y$ direction.

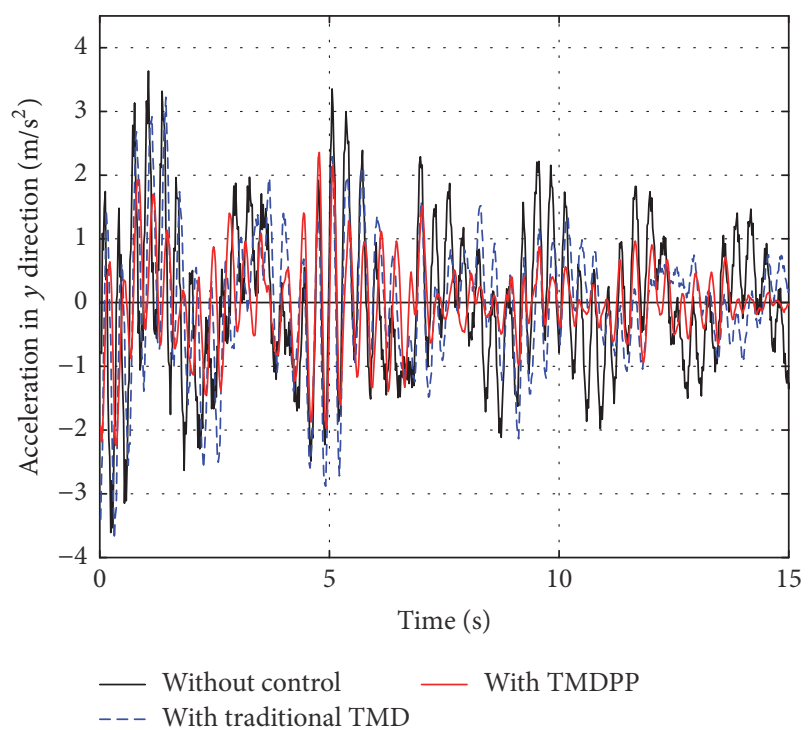

FIgURE 10: Damping comparison of structural acceleration in $y$ direction.

respectively. The structural torsion angle history is shown in Figure 11.

According to the results, it is obvious that the displacement, the acceleration, and the torsion angle are all obviously reduced if the TMDPP is installed on the structural roof, 
TABLE 3: Average damping ratio comparison of TMD and TMDPP.

\begin{tabular}{lcccccc}
\hline & & \multicolumn{2}{c}{ Type and direction } & & \multicolumn{2}{c}{ TMDPP } \\
Damping ratio (\%) & $x$ & Traditional TMD & & $x$ & Torsional \\
\hline Amplitude of displacement & 12.21 & 10.55 & -0.29 & 33.24 & 40.36 & 35.43 \\
Energy of displacement & 16.96 & 25.36 & 14.38 & 69.94 & 73.25 & 71.67 \\
Amplitude of acceleration & 5.16 & -3.72 & 17.4 & 40.62 & 72.86 & 27.15 \\
Energy of acceleration & 2.19 & 12.82 & 8.86 & 25.28 & 60.49 & 38.35 \\
\hline
\end{tabular}

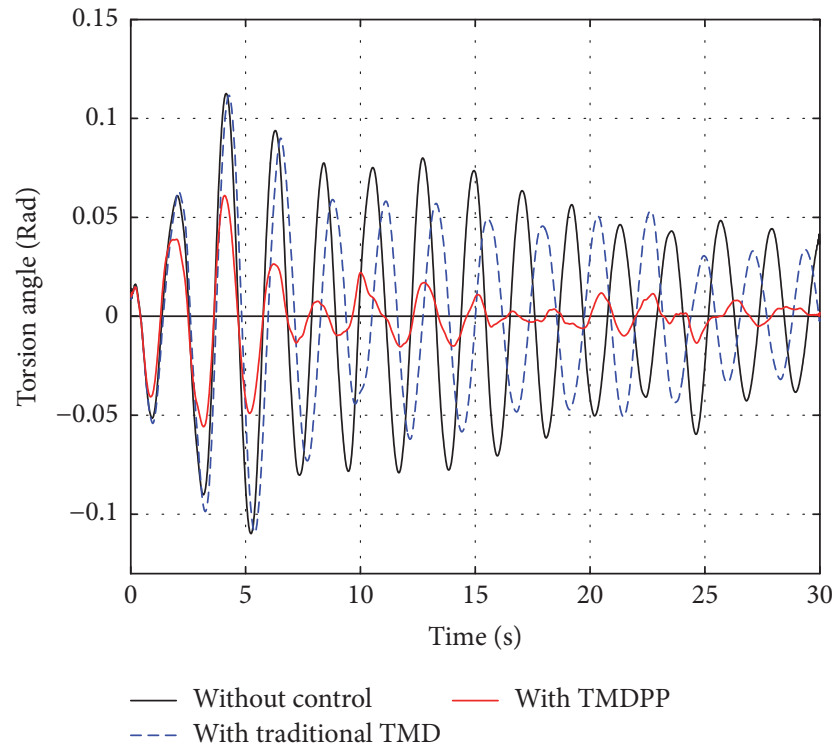

FIGURE 11: Damping comparison of structural torsion angle.

and the damping effect is superior to the traditional TMD. It is worth noting that the responses of the main structure maybe exceed the response of uncontrolled structure at the initial stage or the intense stage of the earthquake because the frequency spectrum is complex and changes rapidly and the traditional TMD cannot complete tuning control timely and promptly. Hence, it is necessary to consider this unsafe possibility in the practical application of TMD. On the contrary, TMDPP can effectively operate once earthquake occurs since all the mass blocks and the torsional pendulums can collaborate in multiple directions, so it has good enough performance. In addition, the damping effect of torsional response is inferior if the traditional TMD is applied, but the damping capacity of the TMDPP is very prominent.

In order to specifically compare the performance of the traditional TMD and TMDPP, the average damping ratio in different directions and all the ground motions are shown in Table 3. In the results, the amplitude damping ratio is the ratio of the difference of the maximum response before and after installing TMD or TMDPP to the maximum value of the uncontrolled structure. The energy damping ratio is the ratio of the difference of the envelope area of response history before and after installing TMD or TMDPP to the envelope area of uncontrolled response.

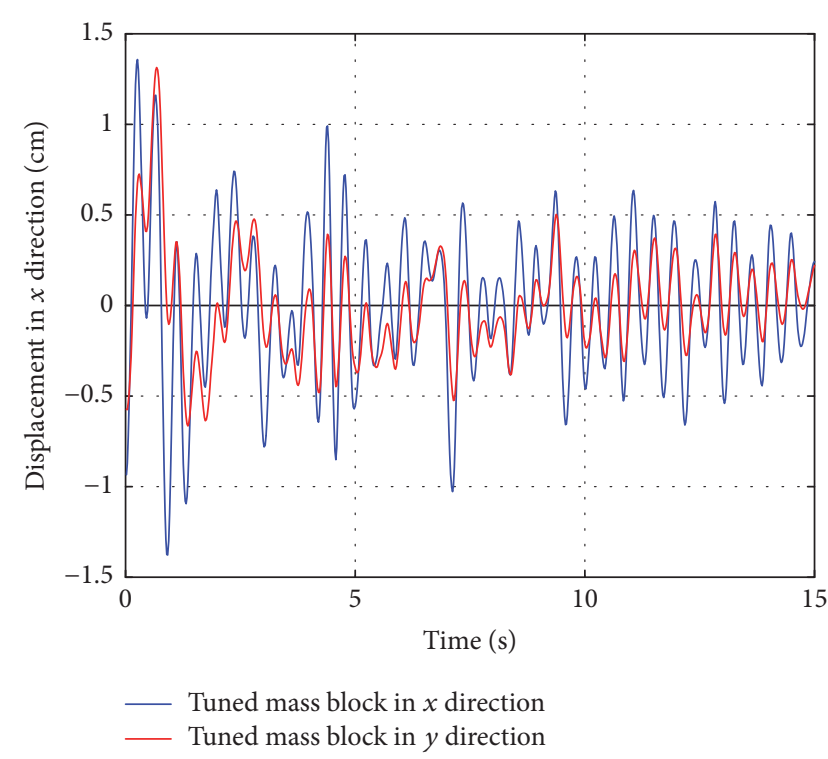

FIGURE 12: Displacement history of tuned mass blocks in $x$ direction.

It can be seen that the damping ratio of the structural acceleration and structural angular acceleration in $y$ direction maybe slightly decrease if the traditional TMD is installed only on the $x$ direction for the eccentric structure, and this phenomenon brings about adverse effects for structural safety. On the contrary, the damping effect of the TMDPP is prominent and the corresponding responses in any direction are significantly reduced, so the multidimensional control for asymmetric structure is realized.

Due to the translation-torsion coupling vibration is generated, the tuned mass blocks not only move in the installation direction but also move in the orthogonal horizontal direction, driven by the torsional pendulums and the poles. The displacement histories of the tuned mass blocks installed in different directions are shown in Figures 12 to 13.

It can be seen that the displacements of the tuned mass block installed in $x$ direction are always larger than the corresponding results of the tuned mass block installed in $y$ direction because the pole length in $x$ direction is longer and the swing distance is larger. In addition to the above factors, the structural response in $y$ direction should be larger since the structure resistance in $y$ direction is weak, so the tuned mass block installed in $x$ direction reduces the dynamic amplitude adaptively and sufficiently due to its excellent mobility in $y$ direction. 


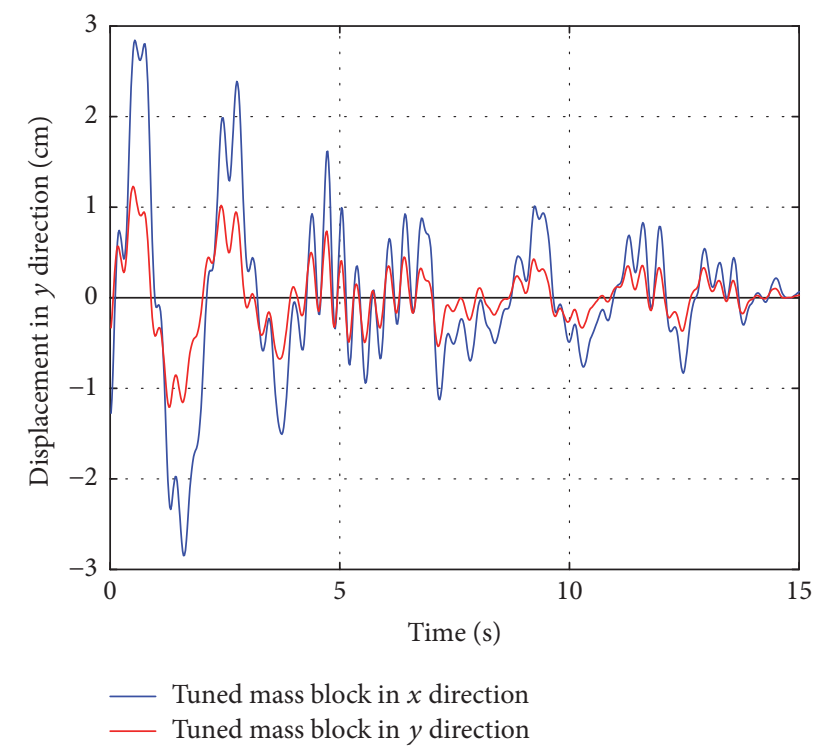

FIGURE 13: Displacement history of tuned mass blocks in $y$ direction.

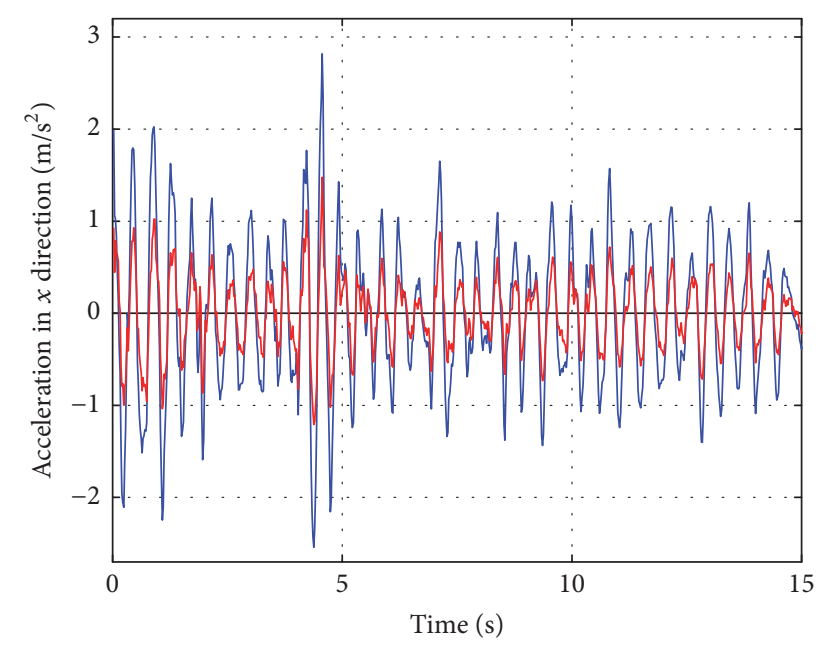

- Tuned mass block in $x$ direction
Tuned mass block in $y$ direction

FIGURE 14: Acceleration history of tuned mass blocks in $x$ direction.

The acceleration histories of the tuned mass blocks installed in different directions are shown in Figure 14. Since the torsion poles are rigid, the variation trend of the acceleration of the tuned mass blocks in the two horizontal directions is similar, and the responses vary dramatically.

The torsion angle histories of the torsional pendulums in the two orthogonal directions are shown in Figure 15, and the corresponding angle acceleration results are shown in Figure 16. It is evident that the pendular motion of the torsional pendulums changes rapidly and the energy dissipation in the torsional direction is more significant, so the damping capacity of the TMDPP is further verified.

Although the current TMDPP has a good damping effect, in order to study the influence of design parameters on the

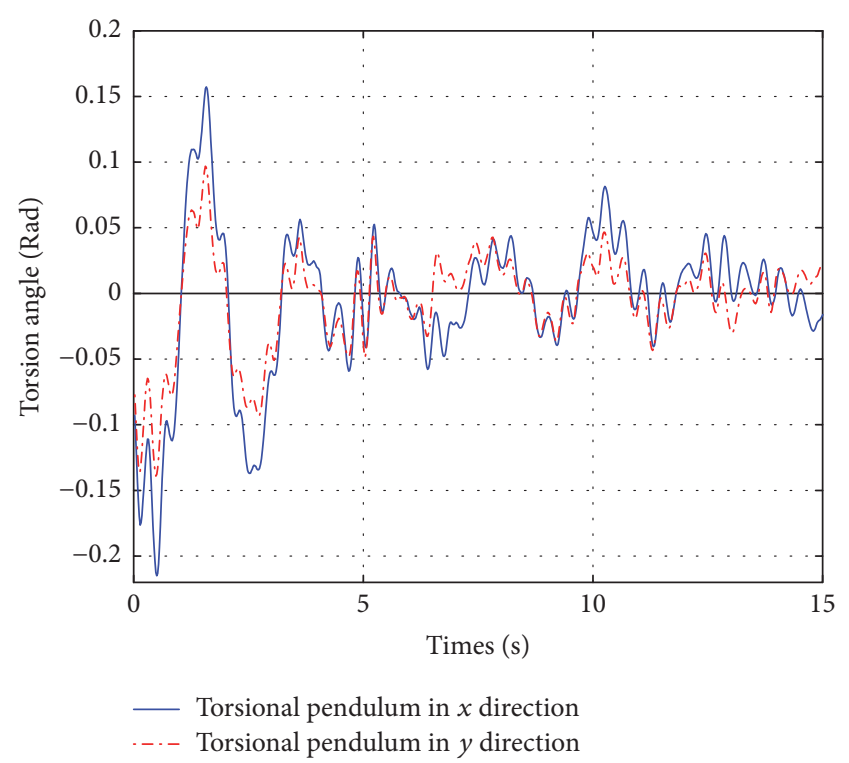

FIgURE 15: Torsion angle history of the torsional pendulums.

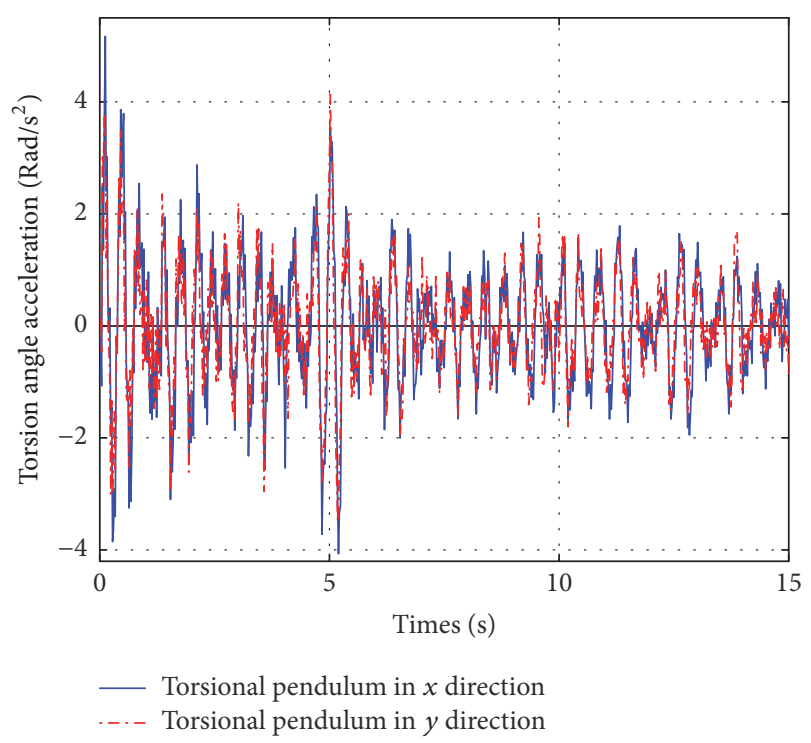

FIGURE 16: Torsion angle acceleration history of the torsional pendulums.

control performance, the damping effect of different length coefficient, total mass, and mass distribution coefficient of TMDPP is studied, and the time analysis of the structure system with different TMDPPs is carried out. For comparison purposes, the increasing rate of the damping ratios of different schemes to damping ratio of the original scheme is calculated and listed in Table 4 . The following conclusions can be obtained from the damping effect analysis.

Assuming the pole length is constant, if the tuned mass blocks are located closer to the torsion shaft (i.e., the length conversion factor of length $\beta_{1}$ and $\beta_{2}$ decreases), the better damping effect can be obtained. However, the sufficient movement amplitude of TMD and the actual 
TABLE 4: Increasing rate of damping ratio of the TMDPPs with different design parameters.

\begin{tabular}{lcccccc}
\hline & \multicolumn{3}{c}{ Larameters } \\
$\begin{array}{l}\text { Increasing rate } \\
(\%)\end{array}$ & $\begin{array}{c}\text { Length conversion factor of } \\
\text { length }\end{array}$ & \multicolumn{5}{c}{ Mass ratio of TMDPP to structure } \\
& $\beta_{1}=1 / 9$ & $\beta_{1}=4 / 6$ & $m_{1}=m_{3}=0.01$ & $m_{1}=m_{3}=0.02$ & $m_{1}=m_{3}=0.01$ & $m_{1}=m_{3}=0.025$ \\
& $\beta_{2}=1 / 7$ & $\beta_{2}=3 / 5$ & $m_{2}=m_{4}=0.015$ & $m_{2}=m_{4}=0.005$ & $m_{2}=m_{4}=0.005$ & $m_{2}=m_{4}=0.015$ \\
\hline $\begin{array}{l}\text { Displacement in } \\
x \text { direction }\end{array}$ & 1.87 & -0.78 & -0.58 & 0.66 & -0.49 & 1.11 \\
$\begin{array}{l}\text { Displacement in } \\
y \text { direction }\end{array}$ & 0.79 & -0.49 & -0.34 & 0.25 & -0.37 & 0.53 \\
$\begin{array}{l}\text { Acceleration in } \\
\text { direction }\end{array}$ & 24.47 & -17.3 & -6.52 & 3.38 & -10.56 & 13.46 \\
$\begin{array}{l}\text { Acceleration in } \\
y \text { direction }\end{array}$ & 26.09 & -32.36 & -7.09 & 4.46 & -20.94 & 20.73 \\
Torsion angle & 1.12 & -0.43 & -0.31 & 0.33 & -0.35 & 0.74 \\
\hline
\end{tabular}

space conditions should be fulfilled. If the weight of the tuned mass blocks and the torsional pendulums increase, the damping effect can be improved significantly, but it is usually difficult to be achieved, limited to practical conditions and structural design requirement. Assuming the total weight of the TMDPP is constant, it is helpful to improve the damping effect of acceleration by raising the weight percentage of tuned mass blocks, but the improvement of displacement and torsion angle is limited. In summary, the damping capacity of TMDPP can be appropriately enhanced by adjusting the length conversion factor of length and the mass distribution ratio. Taking into account the actual situation and the engineering demand, the initial scheme in this study is acceptable and sufficiently effective, so it can be utilized in practice.

\section{Conclusion}

Although the traditional tuned mass damper is continuously improved and there is a significant improvement in multifrequency tuning capability and stability, the torsional control performance for asymmetry is still deficient. A new tuned device TMDPP which has tuned mass blocks, torsional pendulums, and poles is proposed. It is installed in two horizontal discretions, and the horizontal and torsional coupled vibration control is realized by the translation and rotation of mass blocks and pendulums. The dynamic equation for the eccentric structure with TMDPP is established and the corresponding numerical analysis is carried out.

The structural responses such as displacement, acceleration, and torsional angle with different control schemes are studied; the damping effect and the movement characteristics of each parts on the TMDPP are analyzed. The results show that tuned mass blocks and the torsional pendulums can adequately dissipate the translational energy and torsional energy of the main structure, and the damping effect is more superior to the traditional TMD. In addition, the structural responses maybe increase if the traditional TMD is used when the eccentric structure is subjected to earthquake since the tuning capability and adaptability are deficient. On the contrary, the similar adverse phenomenon will not occur if the TMDPP is utilized. The main design parameters of TMDPP are analyzed, and the results show that the length conversion factor of pole length and the mass distribution ratio are the essential influencing factors in damping effect.

In conclusion, the construction of the TMDPP is simple, and its mechanism is clear. It is suitable for the seismic control of eccentric and irregular structures. Nevertheless, the optimal design, the manufacturing process, and the engineering feasibility should be intensively studied by finite element analysis and dynamic experiment, and the relevant research will be launched in the future.

\section{Competing Interests}

The authors declare that there is no conflict of interests regarding the publication of this paper.

\section{Acknowledgments}

This work is partially supported by Natural Science Foundation of China under Grant nos. 51478024 and 51108009 and Foundation of Beijing Key Lab of Earthquake Engineering and Structural Retrofit under Grant no. USDE201403.

\section{References}

[1] R. W. Clough and J. Penzien, Dynamics of Structures, McGrawHill, New York, NY, USA, 1993.

[2] A. M. Chandler and G. L. Hutchinson, "Torsional coupling effects in the earthquake response of asymmetric buildings," Engineering Structures, vol. 8, no. 4, pp. 222-236, 1986.

[3] W.-H. Lin, A. K. Chopra, and J. C. De La Llera, "Accidental torsion in buildings: analysis versus earthquake motions," Journal of Structural Engineering, vol. 127, no. 5, pp. 475-481, 2001.

[4] H. Shakib and R. Z. Tohidi, "Evaluation of accidental eccentricity in buildings due to rotational component of earthquake," Journal of Earthquake Engineering, vol. 6, no. 4, pp. 431-445, 2002.

[5] G. W. Housner, L. A. Bergman, T. K. Caughey et al., "Structural control: past, present, and future," Journal of Engineering Mechanics, vol. 123, no. 9, pp. 897-971, 1997. 
[6] T. T. Song and G. F. Dargush, Passive Energy Dissipation Systems in Structural Engineering, John Wiley \& Sons, New York, NY, USA, 1997.

[7] A. A. Markou, G. Oliveto, and A. Athanasiou, "Response simulation of hybrid base isolation systems under earthquake excitation," Soil Dynamics and Earthquake Engineering, vol. 84, pp. 120-133, 2016.

[8] C.-C. Chou and Y.-C. Chen, "Development of steel dual-core self-centering braces: quasi-static cyclic tests and finite element analyses," Earthquake Spectra, vol. 31, no. 1, pp. 247-272, 2015.

[9] F. Mazza, M. Mazza, and A. Vulcano, "Displacement-based seismic design of hysteretic damped braces for retrofitting inelevation irregular r.c. framed structures," Soil Dynamics and Earthquake Engineering, vol. 69, pp. 115-124, 2015.

[10] N. Hoang, Y. Fujino, and P. Warnitchai, "Optimal tuned mass damper for seismic applications and practical design formulas," Engineering Structures, vol. 30, no. 3, pp. 707-715, 2008.

[11] K. Xu and T. Igusa, "Dynamic characteristics of multiple substructures with closely spaced frequencies," Earthquake Engineering \& Structural Dynamics, vol. 21, no. 12, pp. 1059-1070, 1992.

[12] M. Abé and T. Igusa, "Tuned mass dampers for structures with closely spaced natural frequencies," Earthquake Engineering and Structural Dynamics, vol. 24, no. 2, pp. 247-261, 1995.

[13] C. Li, X. Xiong, and B. Cheng, "The optimum MTMD based on parameter combinations and acceleration transfer function," Journal of Vibration and Shock, vol. 20, no. 3, pp. 50-54, 2001.

[14] C. X. Li, "Performance of multiple tuned mass dampers for attenuating undesirable oscillations of structures under the ground acceleration," Earthquake Engineering and Structural Dynamics, vol. 29, no. 9, pp. 1405-1421, 2000.

[15] R. S. Jangid and T. K. Datta, "Performance of multiple tuned mass dampers for torsionally coupled system," Earthquake Engineering and Structural Dynamics, vol. 26, no. 3, pp. 307-317, 1997.

[16] B. K. Han and C. X. Li, "Evaluation of multiple dual tuned mass dampers for structures under harmonic ground acceleration," International Journal of Structural Stability and Dynamics, vol. 6, no. 1, pp. 59-75, 2006.

[17] H. Garrido, O. Curadelli, and D. Ambrosini, "Improvement of tuned mass damper by using rotational inertia through tuned viscous mass damper," Engineering Structures, vol. 56, pp. 21492153, 2013.

[18] M. P. Singh, S. Singh, and L. M. Moreschi, "Tuned mass dampers for response control of torsional buildings," Earthquake Engineering and Structural Dynamics, vol. 31, no. 4, pp. 749-769, 2002.

[19] A. S. Ahlawat and A. Ramaswamy, "Multiobjective optimal absorber system for torsionally coupled seismically excited structures," Engineering Structures, vol. 25, no. 7, pp. 941-950, 2003.

[20] C. Li and W. Qu, "Optimum properties of multiple tuned mass dampers for reduction of translational and torsional response of structures subject to ground acceleration," Engineering Structures, vol. 28, no. 4, pp. 472-494, 2006.

[21] J. L. Almazán, G. Espinoza, and J. J. Aguirre, "Torsional balance of asymmetric structures by means of tuned mass dampers," Engineering Structures, vol. 42, pp. 308-328, 2012.

[22] J.-L. Lin, K.-C. Tsai, and Y.-J. Yu, "Bi-directional coupled tuned mass dampers for the seismic response control of twoway asymmetric-plan buildings," Earthquake Engineering and Structural Dynamics, vol. 40, no. 6, pp. 675-690, 2011.
[23] J.-F. Wang and C.-C. Lin, "Seismic performance of multiple tuned mass dampers for soil-irregular building interaction systems," International Journal of Solids and Structures, vol. 42, no. 20, pp. 5536-5554, 2005.

[24] H. X. He, E. Z. Han, and Y. W. Lv, "Coupled vibration control of tuned mass damper in both horizontal and torsional direction," Applied Mechanics and Materials, vol. 578-579, no. 2, pp. 10001006, 2014.

[25] S. J. Sun and G. X. Chen, "Synthesis method for estimation of rotation components of ground motion," Journal of Seismology, vol. 18, no. 1, pp. 19-24, 1988.

[26] J. J. Wang and J. R. Jiang, "Estimation of response spectrum for rotational ground motions," Earthquake Engineering \& Engineering Vibration, vol. 13, no. 3, pp. 7-16, 1993. 


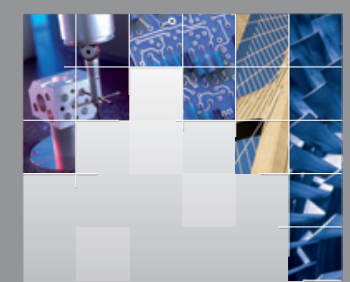

\section{Enfincering}
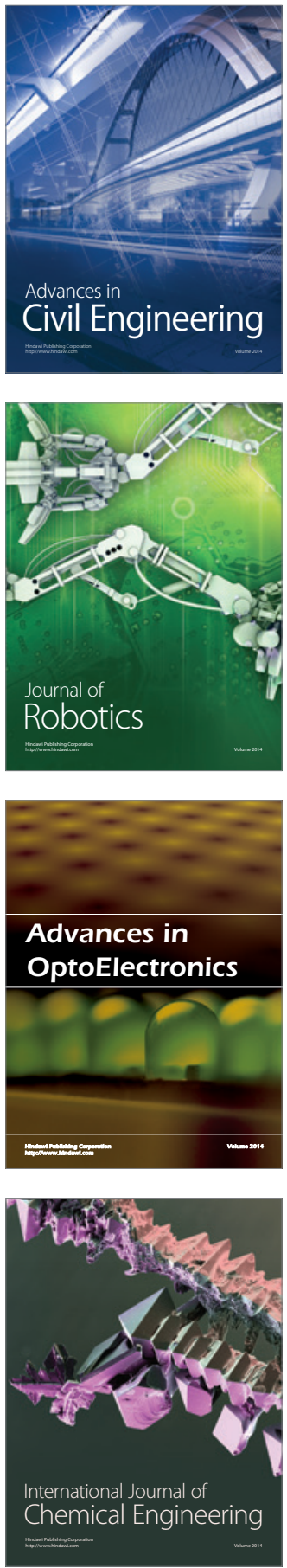

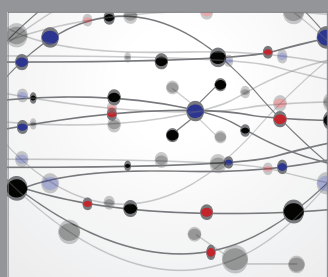

The Scientific World Journal

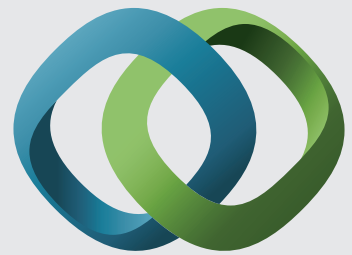

\section{Hindawi}

Submit your manuscripts at

https://www.hindawi.com
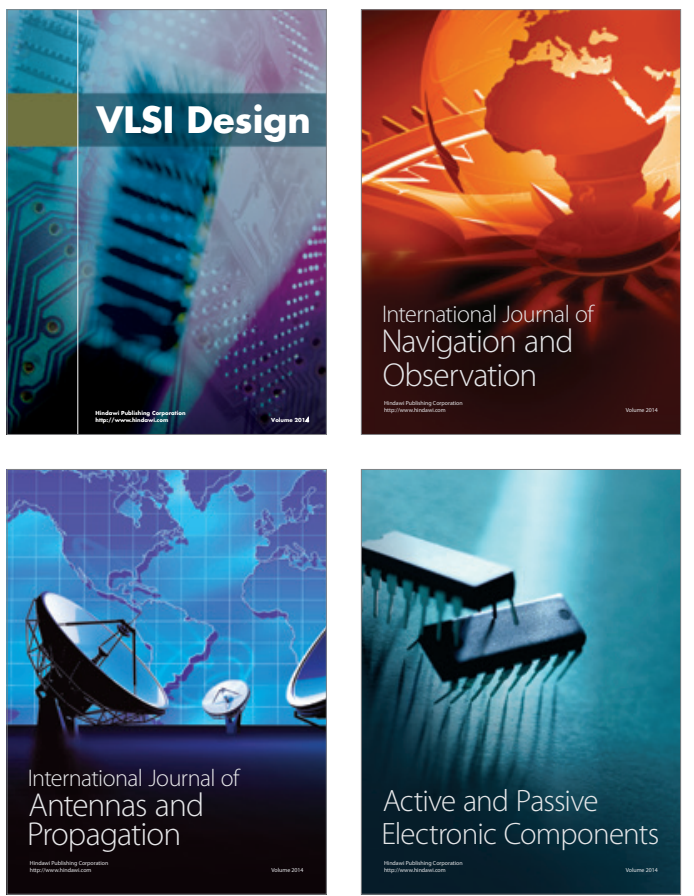
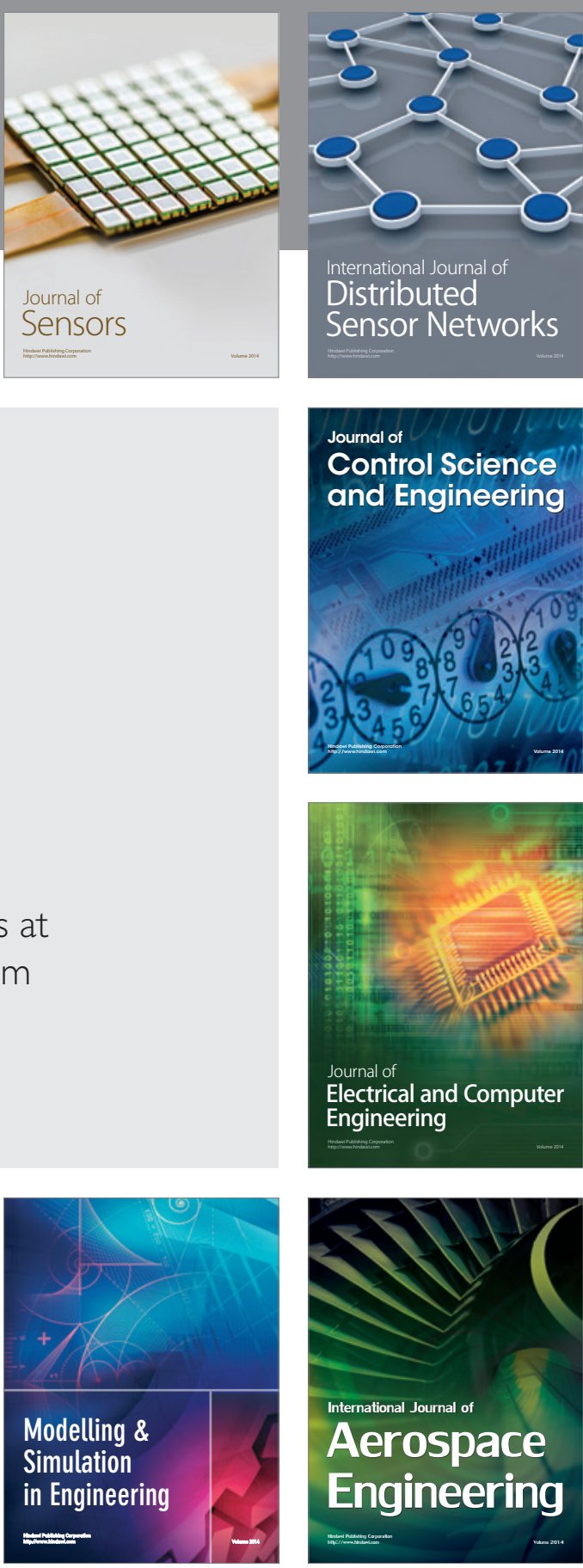

International Journal of

Distributed

Sensor Networks

$-$

Joumal of

Control Science

and Engineering
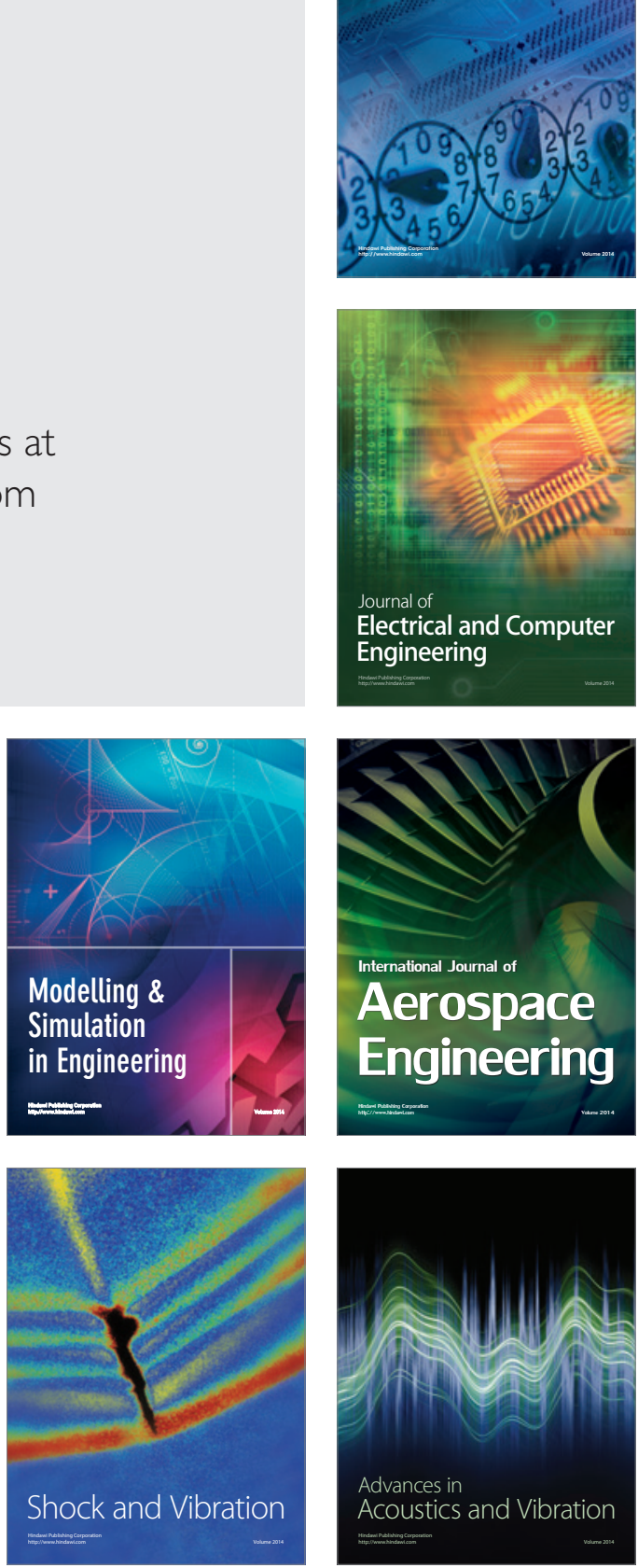